\title{
Case Reportt
}

\section{Negative-pressure pulmonary edema and hemorrhage associated with upper airway obstruction*}

\author{
Edema e hemorragia pulmonar por pressão negativa \\ associados à obstrução das vias aéreas superiores
}

Ricardo Kalaf Mussi ${ }^{1}$, Ivan Felizardo Contrera Toro ${ }^{2}$

\begin{abstract}
Negative-pressure pulmonary edema accompanied by hemorrhage as a manifestation of upper airway obstruction is an uncommon problem that is potentially life-threatening. The principal pathophysiological mechanism involved is the generation of markedly negative intrathoracic pressure, which leads to an increase in pulmonary vascular volume and pulmonary capillary transmural pressure, creating a risk of disruption of the alveolar-capillary membrane. We report the case of an adult male with diffuse alveolar hemorrhage following acute upper airway obstruction caused by the formation of a cervical and mediastinal abscess resulting from the insertion of a metallic tracheal stent. The patient was treated through drainage of the abscess, antibiotic therapy, and positive pressure mechanical ventilation. This article emphasizes the importance of including this entity in the differential diagnosis of acute lung injury after procedures involving upper airway instrumentation.
\end{abstract}

Keywords: Hemorrhage; Pulmonary edema; Airway obstruction; Abscess; Prostheses and implants.

\section{Resumo}

0 edema pulmonar por pressão negativa associado à hemorragia como manifestação de obstrução das vias aéreas superiores é um problema incomum com potencial risco de morte. 0 principal mecanismo fisiopatológico envolvido é a geração de uma acentuada pressão negativa intratorácica que eleva tanto o volume vascular como a pressão transmural capilar pulmonar, causando risco de ruptura da membrana alvéolo-capilar. Relatamos o caso de um paciente do sexo masculino com hemorragia alveolar difusa após obstrução aguda das vias aéreas superiores causada pela formação de um abscesso cervical e mediastinal decorrente do implante de uma órtese traqueal metálica. 0 paciente foi tratado com drenagem do abscesso, antibioticoterapia e ventilação mecânica com pressão positiva. Este artigo enfatiza a importância de incluir essa entidade no diagnóstico diferencial da lesão pulmonar aguda após procedimentos que envolvam a manipulação das vias aéreas superiores.

Descritores: Hemorragia; Edema pulmonar; Obstrução das vias respiratórias; Abscesso; Próteses e implantes.

\section{Introduction}

Negative-pressure pulmonary edema (NPPE), although uncommon, is a known entity related to upper airway obstruction. It is frequently underdiagnosed and potentially lethal. It occurs most frequently in patients with laryngospasm after procedures performed under general anesthesia. ${ }^{(1)}$

The pathogenesis of NPPE is multifactorial, and the highly negative intrathoracic pressure associated with upper airway obstruction plays an important role. However, negative-pressure pulmonary hemorrhage has rarely been reported. ${ }^{(2,3)}$

We report a case of negative-pressure pulmonary hemorrhage related to an obstructive upper airway process caused by a cervical and mediastinal abscess after the insertion of a self-expanding metallic tracheal stent for the treatment of postintubation tracheal stenosis.

\section{Case report}

A 25-year-old male professional athlete with postintubation tracheal stenosis underwent tracheal dilatation followed by the placement of a self-expanding metallic stent in the upper third of the trachea.

Seven days after the implantation, the patient presented fever accompanied by subcutaneous emphysema in the cervical region. The leukocyte count was 25,000, with $8 \%$ rods. Computed tomography of the neck and chest

\footnotetext{
* Study carried out at the Universidade Estadual de Campinas - Unicamp, State University at Campinas - Campinas, Brazil.

1. Attending Physician in the Department of Thoracic Surgery. Universidade Estadual de Campinas - Unicamp, State University at Campinas - Campinas, Brazil.

2. Professor in and Coordinator of the Department of Thoracic Surgery. Universidade Estadual de Campinas - Unicamp, State University at Campinas - Campinas, Brazil.

Correspondence to: Ricardo Kalaf Mussi. Rua Copaíba, 810, Jd. Miriam, CEP 13098-347, Campinas, SP, Brasil.

Tel 5519 3521-9441. E-mail: rkalaf@fcm.unicamp.br
}

Submitted: 7 March 2007. Accepted, after review: 8 August 2007. 
revealed marked prominence of the posterior wall of the trachea immediately below the tracheal stent (Figures 1a and 1b). Bronchoscopy was performed under sedation ( $3 \mathrm{mg}$ of midazolam) and topical laryngotracheal anesthesia with 1\% lidocaine. The bronchoscopic examination revealed that the stent was properly positioned, and that there was significant prominence along the lower edge of the membranous wall. During the procedure, there was no bleeding or other complications, and $500 \mathrm{~mL}$ of saline solution were administered for fluid replacement. Immediately after the endoscopic examination, the patient presented respiratory insufficiency, together with noisy respiration, suggesting the existence of an obstructive upper airway process requiring vigorous inspiratory effort. The patient was initially treated with oxygen (delivered via an oxygen mask at $10 \mathrm{~L} / \mathrm{min}$ ) and intravenous corticosteroid therapy.

Since there was no improvement in the clinical profile, the patient underwent translaryngeal intubation with a 7F catheter through the metallic implant. There was immediate outflow of a large quantity of hemorrhagic discharge through the orotracheal tube.

Arterial blood gas analysis with a fraction of inspired oxygen $\left(\mathrm{FiO}_{2}\right)$ of 1.0 revealed the following: $\mathrm{pH}, 7.35$; arterial carbon dioxide tension $\left(\mathrm{PaCO}_{2}\right.$ ), $39 \mathrm{mmHg}$; arterial oxygen tension $\left(\mathrm{PaO}_{2}\right), 80 \mathrm{mmHg}$; bicarbonate $\left(\mathrm{HCO}_{3}\right), 20$; base excess (BE), -3.3; and arterial oxygen saturation $\left(\mathrm{SaO}_{2}\right), 87 \%$. The electrocardiogram results revealed normal sinus rhythm. The chest X-ray performed in the operating room revealed bilateral pulmonary consolidation, predominantly in the upper and middle lung fields, with no signs of heart enlargement (Figure 2a). At that time, pulmonary auscultation revealed bilateral diffuse rales, whose distribution was consistent with the radiological profile. A second bronchoscopy revealed diffuse bleeding from the lobar bronchi, predominantly from the upper bronchi.

In view of the stability of the respiratory insufficiency, we opted for immediate drainage of the cervical abscess via right anterolateral cervicotomy, followed by the insertion of a 3-way Foley catheter for continuous postoperative irrigation.

There was no hemodynamic instability at any point during the procedure; mean arterial pressure remained between $85-90 \mathrm{mmHg}$, and central venous pressure was $5-7 \mathrm{~cm} \mathrm{H}_{2} \mathrm{O}$ throughout. With an $\mathrm{FiO}_{2}$ of 1.0 under controlled mechanical ventilation, peripheral oxygen saturation ranged from 80 to $85 \%$.

The patient was taken to the intensive care unit, and remained under sedation and continuous mechanical ventilation. No diuretics were given. The chest X-ray and arterial blood gas analysis revealed progressive improvement, and the patient was gradually weaned from mechanical ventilation, being extubated on postoperative day 3.

On postoperative day 5 , the patient underwent computed tomography of the neck and chest. The results showed that the cervical abscess was controlled but identified areas of asymmetric consolidation in both upper lobes (Figure 2b), as well as dense fluid content, consistent with purulent


Figure 1 - a) Computed tomography scan of the chest revealing right subcutaneous emphysema, retrotracheal cervical abscess, and the metallic stent; and b) Computed tomography of the chest revealing a mediastinal abscess with marked prominence of the posterior wall of the trachea. 

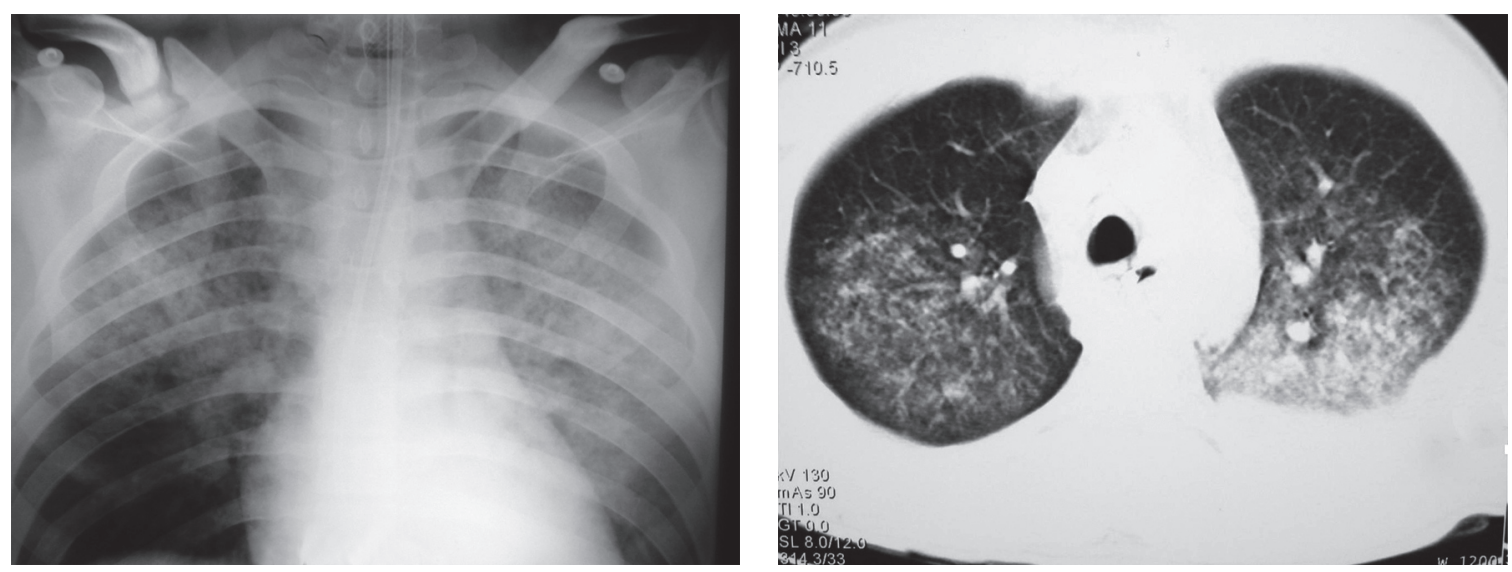

Figure 2 - a) Chest X-ray taken in the operating room and revealing bilateral pulmonary consolidation, predominantly in the lung apex and middle lung field; and b) Computed tomography of the chest revealing areas of asymmetric consolidation in both upper lobes.

collection, in the mediastinum and left pleural space. The patient was again taken to the operating room in order to undergo left video-assisted thoracoscopy for surgical drainage of both collections. In addition, the diagnosis of pleural empyema and bacterial mediastinitis was confirmed. Staphylococcus aureus grew in the culture of the material collected during the surgical procedure.

The evolution of the systemic infectious process was favorable. A control computed tomography scan taken on postoperative day 17 revealed complete remission of the pleural, pulmonary, and mediastinal profile (Figure 3). The patient was then discharged from the hospital.

\section{Discussion}

Laryngotracheal injuries following translaryngeal intubation or tracheostomy secondary to lack of cuff pressure control are relatively common problems, and some can evolve to symptomatic obstructive processes, requiring therapeutic procedures.

Endoscopic treatments and surgical reconstructions can present immediate complications, principally upper airway obstruction.

The formation of noncardiogenic pulmonary edema secondary to various forms of upper airway obstruction has been observed. Shwartz, for example, found the incidence of such edema to be $11 \%$ in adults. ${ }^{(3)}$

The principal physiological mechanism involved in the formation of this type of edema is the generation of markedly negative intrathoracic pressure, which leads to an increase in pulmonary vascular volume, microvascular hydrostatic pressure, and pulmonary capillary transmural pressure. Transudation from the pulmonary capillary space to the interstitium progresses to the formation of pulmonary edema. ${ }^{(4)}$

Rupture of the alveolar capillary membrane (due to the increased negative intrathoracic pressure) might also be involved in NPPE, causing an increase in capillary permeability as well as pulmonary edema. ${ }^{(5)}$ In addition, the vigorous inspiratory effort of an individual with large muscle mass against an obstructed airway (Mueller maneuver), ${ }^{(3)}$ as in the present report, can have a significant influence on the development of NPPE.

Acute respiratory failure releases catecholamines, resulting in increased blood volume in the lung caused by the translocation of blood from the systemic circulation to the pulmonary circulation. This is due to the increase in systemic arterial pressure resulting from the vasoconstriction caused by the availability of circulating amines, as well as to the increase in the venous return due to the reduction of the right atrial pressure secondary to the transmission of the intrathoracic pressure. ${ }^{(3)}$

There are two types of NPPE: type 1, which is followed by sudden and intense obstruction, such as postextubation laryngospasm and epiglottitis; and type 2, which develops after surgical release of chronic airway obstruction, such as resection of 


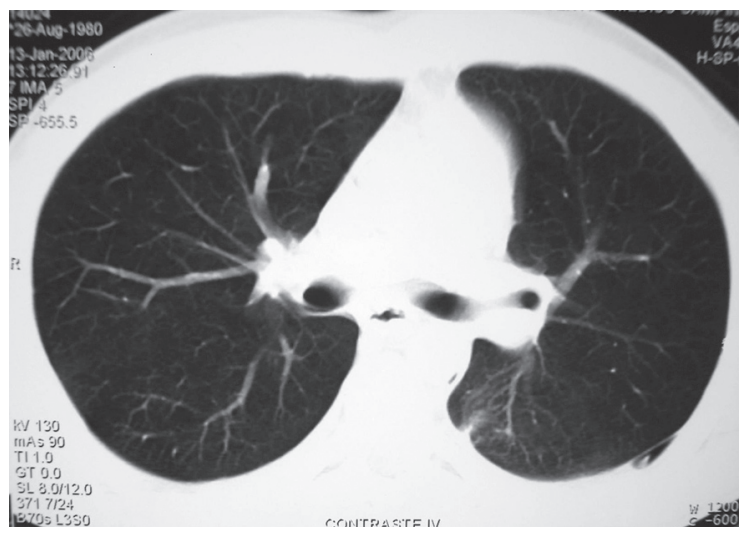

Figure 3 - Computed tomography of the chest on postoperative day 17 revealing complete remission of the pulmonary infiltration.

laryngeal tumors, adenoids/tonsils (adenotonsillectomy), or intrathoracic goiters. ${ }^{(6-9)}$

In type 1 , the alterations predominantly affect venous return and the cardiac index, resulting in fluid transudation to the alveolar space; in type 2, there is loss of auto-positive end-expiratory pressure due to the resolution of the lesion. ${ }^{(9)}$

In the present report, the NPPE was classified as type 1 , and the severe obstructive factor was the combination of the metallic stent, which reduced the tracheal lumen diameter to approximately $20 \mathrm{~mm}$, and the prominence of the posterior wall of the trachea, immediately below the stent, resulting from the purulent collection in the neck.

Capillary transudation of proteinaceous material can be part of the classical description of rosecolored or foaming serosanguineous discharge in NPPE, in which the extreme elevations in transmural pressure disrupt the alveolar-capillary membrane, leading to the transudation of erythrocytes to the alveoli and causing frank hemorrhage. ${ }^{(1)}$

Diffuse alveolar hemorrhage due to negative intrathoracic pressure is an extremely rare phenomenon. ${ }^{(3)}$ Pulmonary capillary damage caused by the stretching force, followed by mechanical rupture of the alveolar-capillary membrane, a condition characteristic of diffuse alveolar lesion, has been postulated as the causal factor - a factor that can be potentiated by the rapid changes in transmural pressure, regardless of pressure peaks. ${ }^{(10)}$

We believe that, in the present report, the inflammatory reaction triggered by the infectious process through the release of interleukins by the activated neutrophils, as well as the increase in vascular permeability elevating the protein extravasation, favored alveolar and interstitial infiltration of the fluid, thereby aggravating the NPPE.

Rapid evolution (in a matter of minutes), with improvement in the first $36 \mathrm{~h}$, and resolution, with a good prognosis, through the use of supplemental oxygen characterize NPPE. However, continuous positive airway pressure is required in 9 to $18 \%$ of all cases, ${ }^{(11)}$ and 34 to $46 \%$ of the patients require controlled mechanical ventilation via orotracheal intubation. ${ }^{(12,13)}$ There have been reports of fatal evolution due to acute respiratory distress syndrome and multiple organ or system failure following upper airway obstruction. ${ }^{(14)}$

Fluid restriction and the use of diuretics in this situation are controversial. ${ }^{(1)}$

Edema accompanied by pulmonary hemorrhage is a rare cause of acute lung injury due to negative pressure in patients with upper airway obstruction. Elimination of the causal factors, together with rapid diagnosis and appropriate treatment, is necessary in order to establish appropriate therapeutic approaches and avoid potentially deleterious iatrogenic complications. ${ }^{(15,16)}$

\section{References}

1. Koh MS, Hsu AA, Eng P. Negative pressure pulmonary oedema in the medical intensive care unit. Intensive Care Med. 2003;29(9):1601-4.

2. Bhavani-Shankar K, Hart NS, Mushlin PS. Negative pressure induced airway and pulmonary injury. Can J Anaesth. 1997;44(1):78-81.

3. Schwartz DR, Maroo A, Malhotra A, Kesselman $H$. Negative pressure pulmonary hemorrhage. Chest. 1999;115(4):1194-7.

4. Van Kooy MA, Gargiulo RF. Postobstructive pulmonary edema. Am Fam Physician. 2000;62(2):401-4.

5. Pavlin DJ, Nessly ML, Cheney FW. Increased pulmonary vascular permeability as a cause of re-expansion edema in rabbits. Am Rev Respir Dis. 1981;124(4):422-7.

6. Willms D, Shure D. Pulmonary edema due to upper airway obstruction in adults. Chest. 1988;94(5):1090-2.

7. Guffin TN, Har-el G, Sanders A, Lucente FE, Nash M. Acute postobstructive pulmonary edema. Otolaryngol Head Neck Surg. 1995;112(2):235-7.

8. McGowan FX, Kenna MA, Fleming JA, O'Connor T. Adenotonsillectomy for upper airway obstruction carries increased risk in children with a history of prematurity. Pediatr Pulmonol. 1992;13(4):222-6.

9. lkeda H, Asato R, Chin K, Kojima T, Tanaka S, Omori K, et al. Negative-pressure pulmonary edema after resection of mediastinum thyroid goiter. Acta Otolaryngol. 2006;126(8):886-8. 
10. West JB, Mathieu-Costello 0. Stress failure of pulmonary capillaries: role in lung and heart disease. Lancet. 1992;340(8822):762-7.

11. Rocker GM, Mackenzie MG, Williams B, Logan PM. Noninvasive positive pressure ventilation: successful outcome in patients with acute lung injury/ARDS. Chest. 1999;115(1):173-7.

12. Butterell H, Riley RH. Life-threatening pulmonary oedema secondary to tracheal compression. Anaesth Intensive Care. 2002;30(6):804-6.

13. Antonelli M, Conti G, Moro ML, Esquinas A, Gonzalez-Diaz $\mathrm{G}$, Confalonieri M, et al. Predictors of failure of noninvasive positive pressure ventilation in patients with acute hypoxemic respiratory failure: a multi-center study. Intensive Care Med. 2001;27(11):1718-28.

14. Adolph MD, Oliver AM, Dejak T. Death from adult respiratory distress syndrome and multiorgan failure following acute upper airway obstruction. Ear Nose Throat J. 1994;73(5):324-7.

15. Westreich R, Sampson 1, Shaari CM, Lawson W. Negativepressure pulmonary edema after routine septorhinoplasty: discussion of pathophysiology, treatment, and prevention. Arch Facial Plast Surg. 2006;8(1):8-15.

16. Ackland GL, Mythen MG. Negative pressure pulmonary edema as an unsuspected imitator of acute lung injury/ ARDS. Chest. 2005;127(5):1867-8. 